\title{
Breast and Thigh Meat Chemical Composition and Fatty Acid Profile in Broilers Fed Diet with Dietary Fat Sources
}

\section{ABM Rubayet Bostami, Hong Seok Mun and Chul-Ju Yang*}

Department of Animal Science and Technology, Sunchon National University, Jeonnam, Republic of Korea

\begin{abstract}
Experiment was conducted to evaluate effects of different fat sources on breast and thigh meat chemical composition and fatty acid profile in broilers. Treatments were 1) DF1: basal diet + soybean oil; 2) DF2: basal diet + chicken fat; 3) DF2: basal diet + tallow; 4) DF3: basal diet + tallow and lard, and 5) DF5: basal diet + lard. Addition of different fat sources had no significant impact on relative organ weight $(P>0.05)$. Breast meat crude fat content was suppressed in DF1 and DF5 relative to DF4 $(P<0.05)$. Total SFA content was downtrended and total PUFA content was elevated in DF1 relative to other groups for both breast and thigh meat $(P<0.05)$. Total MUFA content did not differ in breast meat, however, it was lower in DF1 and DF3 compared to DF2, DF4 and DF5 $(P<0.05)$. The $n-3$ PUFA was not affected by fat sources in breast meat, whereas it was elevated in DF1 relative to DF3, DF4 and DF5 in thigh meat $(P<0.05)$. Breast and thigh meat $n-6$ PUFA was improved in DF1 in comparison to DF2, DF3, DF4 and DF5 in thigh meat $(P<0.05)$. Ratio of PUFA to SFA upgraded in DF1 and DF3, and downgraded in DF2, DF4 and DF5 for breast meat; and upgraded in DF1 than other groups for thigh meat $(P<0.05)$. Breast and thigh meat $n-6$ to $n-3$ PUFA was upgraded in DF1 group compared to other groups $(P<0.05)$. To sum up, results indicated that dietary fat sources with different fatty acid content can significantly influence the breast and thigh meat composition and fatty acid profile without negative impact on the relative organ weight. Where DF1 group exhibited better result based on fatty acid profile and lower breast meat fat content which can be preferred for quality broiler meat production.
\end{abstract}

Keywords: Fat source; Meat composition; Fatty acid profile; Broilers

\section{Introduction}

A considerable elevation of global meat consumption (62\%) has been reported in the last 50 years, with a significant increase occurring in developing countries (three-fold since 1963) and the largest occurring in Asia (Commodity Analysis, Informa UK, 2012). The highest global chicken meat intake is $11.8 \mathrm{~kg}$ per person, whereas in Asia it is $6.4 \mathrm{~kg}$ per person, where the forecast average meat intake for China, Japan, the Republic of Korea, Thailand, Indonesia and India is $11.1,15.8,15.4,13.9,4.5$, and $3.1 \mathrm{~kg} /$ person, respectively (Commodity analysis, Informa UK, 2012). Among different meats, poultry is firmly and continuously increasing worldwide due to its low-price relative to other meat, as well as its healthy aspects. Currently, consumers are more concerned about their food, especially nutritional aspects. Among the nutritional aspects of food, lipid content and fatty acid profile are the most important factors. Chicken meat contains a high protein and lowfat content and deliberated as the principal source of polyunsaturated fatty acids (PUFA) with paramount concentration of n-3 PUFA [1,2]. Fatty acids play a significant role in the health aspects of humans, with long chain fatty acids being beneficial for maintenance of metabolic disorders, as well as for development of the brain and retinal tissue [35]. Food containing higher amounts of PUFA are considered functional and beneficial for the prevention of coronary heart disease and other chronic diseases [6,7]. The most desirable issue influencing the poultry industry is the improvement of performance while developing higher carcass and meat quality, higher meat yield and lower abdominal fat with better composition [8]. The fatty acid content of broiler meat depends on the type of diet intake by the birds. Pigs and broilers fed a sunflower based diet, which contains linoleic acid, show substantially elevated levels of linoleic acid and arachidonic acid in the meat $[9,10]$. It has also been reported that the fatty acid content of poultry, especially the PUFA (ecosapentanoic acid, C20:5n-3; and docosa hexanoic acid, C22:6n-3), can be improved by the addition of oily fish byproducts [11]. Replacement of fish oil with vegetable oil has resulted in a lower level of long chain n-3 fatty acids, eicosapentaenoic acid (EPA) and docosahexaenoic acid (DHA), and higher levels of the C:18 fatty acids, oleic acid, linoleic acid and linolenic acid in tissues of several aquatic studies $[12,13]$. Plant fats generally contain higher amounts of PUFA, while animal fats are composed of relatively higher SFA levels. Differences in the fatty acid composition of the fats will vigorously affect the digestibility and performance of birds. In addition, the composition of dietary lipids is important to chickens because it dictates the actual extent to which it can be utilized as a source of metabolizable energy [14]. Fats with a higher proportion of unsaturated lipids are more easily absorbed than those that may undergo synergism between fat compositions [15-17].

Studies have been conducted to improve the PUFA content in chicken through dietary addition of fat and oil sources that contains PUFA or linoleic acid [9,17], as well as dietary feed additives such as probiotics, prebiotics and natural plant materials [18-22]. However, PUFA tends to be oxidized as it is the first target for the free radical strike upon initiation of lipid peroxidation [23]. Several studies have investigated fat sources of livestock and poultry to investigate their performance, digestibility, and carcass characteristics [8,17,24-26]. There are many plant and animal fat sources with large variations in fatty acid profile or other aspects of their nutritional composition; on the other hand, due to genetic improvement of broiler strains it urges paramount importance of continual research on both the basal and feed additives research. Fatty acid composition can be an important benchmark for the quality of carcass that can potentially be influenced

*Corresponding author: Chul-Ju Yang, Department of Animal Science and Technology, Sunchon National University, 255 Jungangno, Suncheon, Jeonnam 57922, Republic of Korea, Tel: +82-617503235; E-mail: yangcj@scnu.kr

Received April 11, 2017; Accepted May 02, 2017; Published May 09, 2017

Citation: Bostami ABMR, Mun HS, Yang CJ (2017) Breast and Thigh Meat Chemical Composition and Fatty Acid Profile in Broilers Fed Diet with Dietary Fat Sources. J Food Process Technol 8: 672. doi: 10.4172/2157-7110.1000672

Copyright: @ 2017 Rubayet Bostami ABM, et al. This is an open-access article distributed under the terms of the Creative Commons Attribution License, which permits unrestricted use, distribution, and reproduction in any medium, provided the original author and source are credited. 
by the fatty acid profile [25-30]. However, to the best of our knowledge, although several investigations are currently being conducted on feed additives, few studies have investigated basal feed materials, especially the impact of fat sources on meat composition and fatty acid profile in broilers. Therefore, we conducted this comparative study to investigate the effects of fat sources with different fatty acid profiles on carcass characteristics, breast and thigh meat chemical composition and fatty acid profile in broilers.

\section{Materials and Methods}

\section{Experimental design, dietary treatments and bird management}

Experimental birds were reared at the Sunchon National University experimental farm, Suncheon, Republic of Korea. A total of 150 one day-old Ross 308 broiler chicks were randomly allocated into five treatments with five replications (six birds per replicate) in a completely randomized design. The dietary treatments were as follows: 1) DF1: basal diet + soybean oil; 2) DF2: basal diet + chicken fat; 3) DF3: basal diet + beef fat/tallow; 4) DF4: basal diet + beef fat/tallow and pork fat/lard and 5) DF5: basal diet + pork fat/lard. The basal diet was formulated to meet the Nutrient Requirements of Poultry following both the National Research Council (NRC), 1994. Nutrient requirements of poultry. 9th rev. ed. National Academy Press, Washington, DC, USA and the Korean Feeding Standard for poultry (KFS), 2012, NIAS, RDA, Republic of Korea. Birds were reared for a total of 5 weeks in two stages: starter $(0$ to 3 weeks) and finisher ( 4 to 5 weeks). All diets were in mashed form. The chemical composition of the experimental diet was analyzed in triplicate for crude protein (CP), ether extract (EE), moisture and ash as described by the Association of Official Analytical Chemists [31]. The ingredients, chemical composition, and vitamin and mineral content of the basal diets are shown in Table 1 . The PUFA content in soybean oil, chicken fat, tallow, tallow + lard and lard was 58\%, 21\%, 4\%, 7.1\% and $11 \%$, respectively.

The plant oil and animal fat amended with the basal feed ingredients were purchased from local markets in Daejon and Suwon in the Republic of Korea. Chicken fat and beef tallow were collected from the slaughterhouse in which animals were inspected by a veterinarian to ensure that they were disease free and chickens and cattle were slaughtered according to halal methods. After collection of raw fat, it was chopped into smaller chunks of equal size ( 1 inch), then was placed into a frying pan. Water was then added at a $1: 1$ ratio $(\mathrm{W} / \mathrm{W})$, after which the fat was covered with a lid and boiled for 30 minutes, followed by an additional 30 minutes of boiling without the lid. When the boiled fat showed a reddish color indicating that the fatty liquid had been extracted from the solid portions, the heater was switched off. Next, a wire mesh strainer was used to remove the remnants and particles. After straining, three times, the fat was poured into a heatproof ceramic container and covered tightly, then stored for further use. After soybean oil and lard were purchased, they were stored in separate containers and locations until further use. The fatty acid composition of the experimental fat and oil sources was determined by following the direct method for fatty acid methyl ester (FAME) synthesis using a gas chromatograph (GC), with slight modification as previously described [32].

During the experiment, all guidelines for the care and use of animals in research set by the Korean Ministry for Food, Agriculture, Forestry and Fisheries were followed. Broilers were reared in a closed, ventilated, wire-floor caged broiler house $(100 \mathrm{~cm}$ long $\times 90 \mathrm{~cm}$ wide $\times 40 \mathrm{~cm}$ high) with a floor space of $1,125 \mathrm{~cm}^{2} /$ bird. To provide ad libitum feed intake and free access to water, the cages were designed with having a linear feeder in the front and a nipple drinker in the back. The internal temperature of the broiler house was set and maintained at $34^{\circ} \mathrm{C}$ for the first week, after which it was gradually reduced to $23^{\circ} \mathrm{C}$ at $3^{\circ} \mathrm{C}$ per week, where it was maintained until the end of the experimental period. The internal relative humidity was maintained at approximately $50 \%$ throughout the experimental period.

\section{Measurement of carcass characteristics and meat sampling procedure}

At the end of the experiment, two chickens from each replicated pen were randomly selected based on similar body weight, then slaughtered using the halal method with light stunning. Live weight, carcass weight, eviscerated carcass weight, breast and thigh meat weight, and abdominal fat content were weighed. Breast and thigh muscles of birds were removed by trained personnel and weighed individually. The abdominal fat pad (including fat surrounding gizzard, bursa of fabricius, cloaca, and adjacent muscles) was removed and weighed individually for each replication of treatments. After slaughtering the birds, the breast and thigh meat were excised by removing the skin, bones and connective tissue. After weighing, the breast and thigh meat samples were ground separately using a meat grinder. The samples were subsequently divided into aliquots for meat composition and fatty acid content analysis. Finally, the samples were poured into plastic sample bottles and were kept in refrigerator at $-27^{\circ} \mathrm{C}$ for further analysis.

\section{Determination of breast and thigh meat proximate composition}

The chemical composition of the breast and thigh meat samples was analyzed in triplicate for crude protein (CP), ether extract (EE), moisture and ash as described by the Association of Official Analytical Chemists [31].

\section{Determination of breast and thigh meat fatty acids}

The fatty acids compositions of breast and thigh meat were determined by a direct method for fatty acid methyl ester (FAME) synthesis using a slight modification of the method described by O'Fallon et al. [37]. Briefly, $1 \mathrm{~g}$ of minced meat sample was placed into a $15 \mathrm{ml}$ Falcon tube, after which $0.7 \mathrm{ml}$ of $10 \mathrm{~N} \mathrm{KOH}$ in water and $6.3 \mathrm{ml}$ of methanol were added. The tube was then incubated in a $55^{\circ} \mathrm{C}$ water bath for $1.5 \mathrm{~h}$ with vigorous hand-shaking for $10 \mathrm{~s}$ every $30 \mathrm{~min}$ to properly permeate, dissolve and hydrolyze the sample. After cooling to below room temperature in a cold tap water bath, $0.58 \mathrm{ml}$ of $24 \mathrm{~N} \mathrm{H}_{2} \mathrm{SO}_{4}$ in water was added. The tube was then mixed by inversion, after which $\mathrm{K}_{2} \mathrm{SO}_{4}$ precipitated. The sample with the precipitate was incubated again in a $55^{\circ} \mathrm{C}$ water bath for $1.5 \mathrm{~h}$ with vigorous hand-shaking for $10 \mathrm{~s}$ every $30 \mathrm{~min}$. Following FAME synthesis, the tube was cooled in a coldwater bath, after which $3 \mathrm{ml}$ of hexane were added and the tube was vortexed for $5 \mathrm{~min}$ on a multitube vortexer. The tube was subsequently centrifuged for $5 \mathrm{~min}$ at $3000 \times \mathrm{g}$ (HANIL, Combi-514R, Korea), after which the top (hexane) layer containing the FAME was dehydrated through the anhydrous $\mathrm{Na}_{2} \mathrm{SO}_{4}$. The extracted and dehydrated hexane was then concentrated to $1.5 \mathrm{ml}$ and placed into a GC vial for analysis.

The fatty acid composition of the FAME was determined using a Gas Chromatograph (Agilent, 7890A series, 2850 Centerville Road Wilmington, DE 19808-1610 USA) equipped with a flame ionization detector and a Hewlett Packard HP-88 capillary column (J\&W Scientific, USA) with a length of $60 \mathrm{~m}$, a $0.52 \mathrm{~mm}$ internal diameter and a $0.20 \mu \mathrm{m}$ polyethylene glycol-film thickness. Samples were then injected using an auto-sampler (Agilent Technologies 7693, USA). The initial oven temperature was $125^{\circ} \mathrm{C}$, which was held for $1 \mathrm{~min}$, then increased to $145^{\circ} \mathrm{C}$ at $10^{\circ} \mathrm{C} / \mathrm{min}$, where it was held for $26 \mathrm{~min}$, then further increased to $220^{\circ} \mathrm{C}$ at $2^{\circ} \mathrm{C} / \mathrm{min}$, where it was held for $2 \mathrm{~min}$. 
Citation: Bostami ABMR, Mun HS, Yang CJ (2017) Breast and Thigh Meat Chemical Composition and Fatty Acid Profile in Broilers Fed Diet with Dietary Fat Sources. J Food Process Technol 8: 672. doi: 10.4172/2157-7110.1000672

Page 3 of 7

Purified air and hydrogen were applied at a flow rate of $400 \mathrm{ml} / \mathrm{min}$ and $40 \mathrm{ml} / \mathrm{min}$ as the carrier gas, whereas helium was applied at $40 \mathrm{ml} / \mathrm{min}$ as the makeup gas. Both the injector and detector temperature were set at $260^{\circ} \mathrm{C}$, and the split ratio was $30: 1$. Fatty acids were identified by comparison of their retention times with those of a standard FAME mixture (Supelco 37 Component FAME Mix, $10 \mathrm{mg} / \mathrm{ml}$ in $\mathrm{CH}_{2} \mathrm{Cl}_{2}$. Catalog Number 47885-U. Supelco, Bellefonte, PA, USA). Sums and ratios useful for evaluating the nutritional value and healthiness of the fatty acid profile were also determined; specifically, the sum of saturated fatty acids ( $\Sigma$ SFA), monounsaturated fatty acids ( $\Sigma$ MUFA), polyunsaturated fatty acids ( $\Sigma$ PUFA), n-3 fatty acids ( $\Sigma \mathrm{n}-3), \mathrm{n}-6$ fatty acids ( $\Sigma \mathrm{n}-6)$ and the ratios of MUFA to SFA (MUFA/SFA), PUFA to SFA (PUFA/SFA), n-6 to n-3 (n-3/n-6) and hypocholesterolaemic to hypercholesterolaemic $(\mathrm{H} / \mathrm{H})$ fatty acid. The $\mathrm{H} / \mathrm{H}$ ratio was determined as follows: $\mathrm{H} / \mathrm{H}=[($ sum of C18:1 cis-9, C18:2 n-6, C20:4n-6, C18:3 n-3, C20:3n-6, C20:5 n-3, and C22:6 n-3)/(sum of C14:0 and C16:0)].

\section{Statistical analyses}

All data were subjected to ANOVA using the General Linear Models (GLM) function of the Statistical Analysis System (Version 9.1. SAS Institute, Cary, NC, USA). The means were calculated using the least square method and presented with the standard error of the mean (SEM). Differences among means were determined by the Student's t-test. A P $\leq 0.05$ was considered to indicate significance for all analyses, while a $\mathrm{P}<0.10$ was considered a tendency.

\section{Results}

\section{Carcass characteristics and breast and thigh meat composition}

As shown in Table 1, there were no significant differences on the relative organ weights of broilers after dietary addition of different fat sources in broilers $(\mathrm{P}>0.05)$. The proximate composition of breast and thigh meat was shown in Tables 2 and 3. Among chemical composition, there were no significant differences in breast meat moisture, crude protein and crude ash content; however, the crude fat content was lower in the DF1 and DF5 group than that of the DF4 group $(\mathrm{P}<0.05)$ (Table 2 ). In the case of thigh meat, chemical composition among dietary fat treatments did not differ significantly $(\mathrm{P}>0.05)$ (Table 3$)$.

\section{Breast and thigh meat fatty acid profile}

Tables 4 and 5 shows the fatty acid pattern data of breast and thigh meat respectively. Total SFA content was downtrended and total PUFA content was elevated in DF1 group relative to other groups for both breast and thigh meat $(\mathrm{P}<0.05)$. Total MUFA content did not differ in breast meat however, it was lower in DF1 and DF3 compared to DF2, DF4 and DF5 in thigh meat $(\mathrm{P}<0.05)$. The $\mathrm{n}-3$ PUFA was not affected by the fat sources in breast meat, whereas it was elevated in $\mathrm{DF} 1$ relative to DF3, DF4 and DF5 in thigh meat $(\mathrm{P}<0.05)$. Breast and thigh meat n-6 PUFA was improved in DF1 in comparison to DF2, DF3, DF4 and DF5 $(\mathrm{P}<0.05)$. The PUFA to SFA was affected both in breast and thigh meat, higher value being observed in DF1 and DF3 and lower in DF2, DF4 and DF5 for breast meat; and higher in DF1 than other groups for thigh meat $(\mathrm{P}<0.05)$. The breast and thigh meat $\mathrm{n}-6$ to $\mathrm{n}-3$ PUFA was upgraded in the DF1 group compared to the other groups $(\mathrm{P}<0.05)$. Breast meat alfa-linoleic acid was found to be higher in the DF1 group, while eicosapentanoic acid was higher in the DF2 group relative to the other fat groups (DF3, DF4 and DF5) $(\mathrm{P}<0.05)$. Thigh meat ecosapentanoic acid was higher in the DF2 group, while docosahexanoic acid was higher in the DF1 fed group than in other fat groups (DF3, DF4 and DF5) $(\mathrm{P}<0.05)$.

\begin{tabular}{|c|c|c|c|c|c|c|c|}
\hline Items & DF1 & DF2 & DF3 & DF4 & DF5 & SEM & P-value \\
\hline \multicolumn{8}{|c|}{$\%$ of LW } \\
\hline Crop & 0.294 & 0.261 & 0.264 & 0.244 & 0.261 & 0.023 & 0.682 \\
\hline Proventriculus & 0.364 & 0.384 & 0.388 & 0.401 & 0.360 & 0.017 & 0.418 \\
\hline Gizzard & 2.124 & 2.190 & 2.175 & 2.088 & 2.082 & 0.109 & 0.938 \\
\hline Heart & 0.446 & 0.431 & 0.463 & 0.461 & 0.445 & 0.029 & 0.940 \\
\hline Liver & 1.729 & 1.666 & 1.652 & 1.546 & 1.652 & 0.065 & 0.459 \\
\hline Gall bladder & 0.112 & 0.125 & 0.120 & 0.131 & 0.138 & 0.011 & 0.562 \\
\hline Spleen & 0.067 & 0.060 & 0.070 & 0.060 & 0.065 & 0.006 & 0.810 \\
\hline Pancreas & 0.211 & 0.210 & 0.219 & 0.210 & 0.195 & 0.015 & 0.884 \\
\hline Small intestine & 2.349 & 2.268 & 2.463 & 2.151 & 2.266 & 0.086 & 0.186 \\
\hline Large intestine & 0.153 & 0.157 & 0.149 & 0.122 & 0.171 & 0.021 & 0.608 \\
\hline Cecum & 0.414 & 0.417 & 0.476 & 0.422 & 0.503 & 0.029 & 0.136 \\
\hline Kidney & 0.662 & 0.622 & 0.630 & 0.583 & 0.559 & 0.032 & 0.243 \\
\hline Abdominal fat & 1.111 & 1.182 & 0.965 & 1.315 & 1.333 & 0.120 & 0.225 \\
\hline Bursa & 0.221 & 0.223 & 0.207 & 0.208 & 0.182 & 0.030 & 0.884 \\
\hline
\end{tabular}

Significance level considered at $\mathrm{P}<0.05$.

SEM: Standard Error of the Mean.

Dietary treatments: DF1: Basal feed with soybean oil); DF2: Basal feed with chicken fat; DF3: Basal diet with tallow; DF4: Basal diet with tallow and lard (1:8); DF5: Basal feed with pork fat/lard.

Table 1: Effect of dietary fat sources on carcass characteristics and internal organ weight in broilers.

\begin{tabular}{|c|c|c|c|c|c|c|c|}
\hline Items & DF1 & DF2 & DF3 & DF4 & DF5 & SEM & P-value \\
\hline Moisture (\%) & 75.52 & 75.46 & 75.21 & 75.70 & 74.87 & 0.19 & 0.261 \\
\hline Crude protein (\%) & 27.43 & 26.20 & 27.03 & 26.93 & 27.13 & 0.50 & 0.168 \\
\hline Crude fat (\%) & $0.70^{\mathrm{b}}$ & $0.83^{\mathrm{ab}}$ & $0.64^{\mathrm{bc}}$ & $0.91^{a}$ & $0.49^{c}$ & 0.07 & 0.003 \\
\hline Crude Ash (\%) & 1.44 & 1.42 & 1.47 & 1.51 & 1.51 & 0.03 & 0.184 \\
\hline
\end{tabular}

$a, b, c$ Means with different superscripts within the same line are significantly different $(P<0.05)$.

SEM: Standard Error of the Mean.

Dietary treatments: DF1: Basal feed with soybean oil); DF2: Basal feed with chicken fat; DF3: Basal diet with tallow; DF4: Basal diet with tallow and lard (1:8); DF5 Basal feed with pork fat/lard.

Table 2: Effect of dietary fat sources on breast meat proximate composition in broilers. 
Citation: Bostami ABMR, Mun HS, Yang CJ (2017) Breast and Thigh Meat Chemical Composition and Fatty Acid Profile in Broilers Fed Diet with Dietary Fat Sources. J Food Process Technol 8: 672. doi: 10.4172/2157-7110.1000672

Page 4 of 7

\begin{tabular}{|c|c|c|c|c|c|c|c|}
\hline Items & DF1 & DF2 & DF3 & DF4 & DF5 & SEM & P-value \\
\hline Moisture (\%) & 73.61 & 72.74 & 73.02 & 72.50 & 72.13 & 0.76 & 0.594 \\
\hline Crude protein (\%) & 21.53 & 21.22 & 21.51 & 22.10 & 21.98 & 0.28 & 0.342 \\
\hline Crude fat (\%) & 5.21 & 5.90 & 4.71 & 4.75 & 4.10 & 0.54 & 0.337 \\
\hline Crude Ash (\%) & 1.07 & 1.09 & 1.06 & 1.10 & 1.12 & 0.03 & 0.859 \\
\hline
\end{tabular}

a,b,c Means with different superscripts within the same line are significantly different $(P<0.05)$.

SEM: Standard Error of the Mean.

Dietary treatments: DF1: Basal feed with soybean oil); DF2: Basal feed with chicken fat; DF3: Basal diet with tallow; DF4: Basal diet with tallow and lard (1:8); DF5: Basal feed with pork fat/lard.

Table 3: Effect of dietary fat sources on thigh meat proximate composition in broilers.

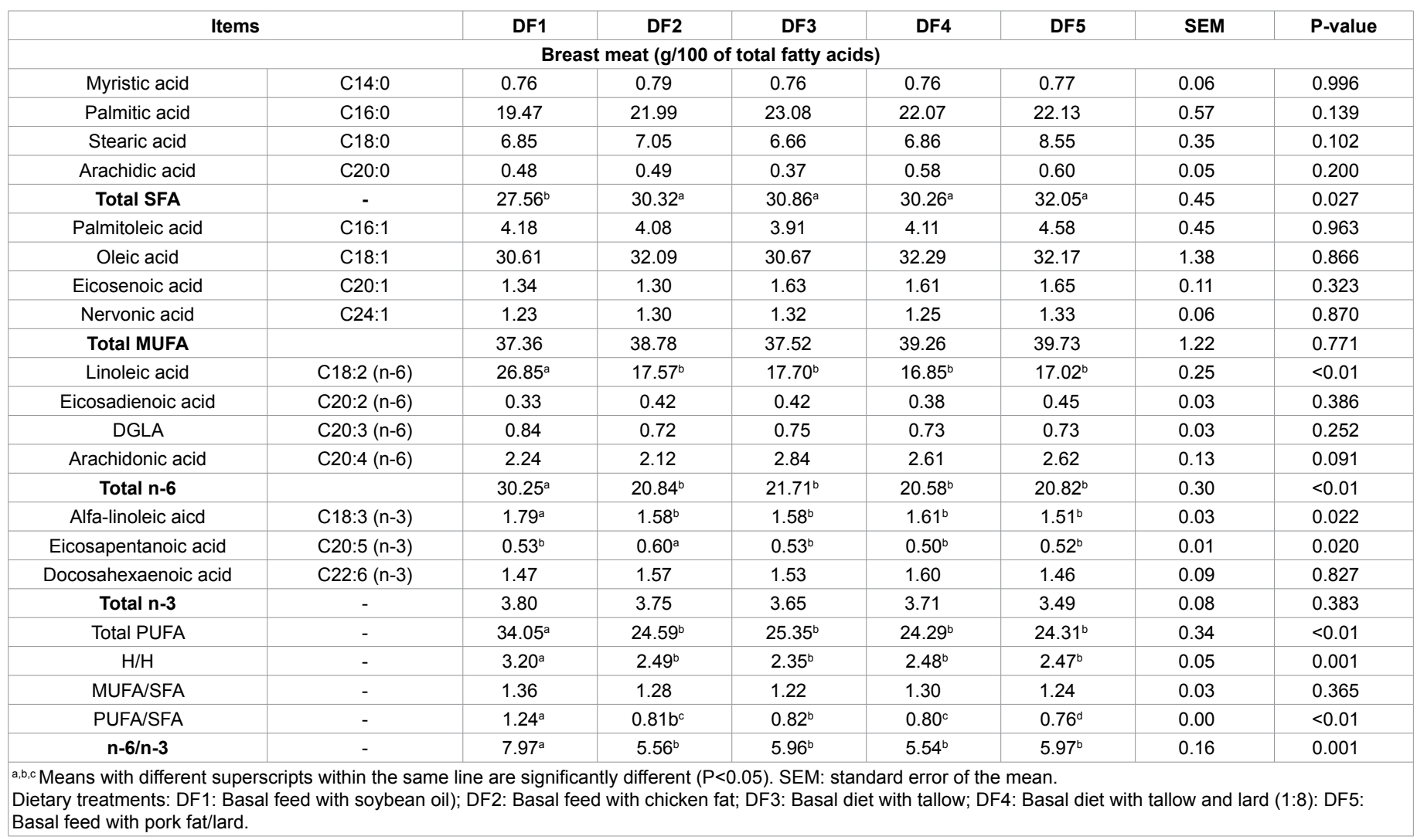

Table 4: Effect of dietary fat sources on breast meat fatty acid content in broilers.

\section{Discussion}

\section{Carcass characteristics and breast and thigh meat composition}

Perpetual development of livestock and poultry industry through nature and nurture imposing to conduct research on both basic feed materials and feed additives. In the present experiment, the effects of fat sources with different fatty acid contents on broiler carcass characteristics, breast and thigh meat composition and fatty acid profile were investigated. There was no significant differences in carcass characteristics and internal organ weight in the different fat sources group. Supporting to the present study, dietary addition of soybean oil, animal/vegetable fat blend, rapeseed oil, and processed fat product in the broilers unable to affect breast and thigh meat proportion and abdominal fat in the previous study [24]. The impact of fat sources on carcass characteristics usually impacted due to fatty acid composition and digestibility differences. Ketels and DeGroote [16] demonstrated the superiority of vegetable oils to animal fats; the main reason for the better result is the higher digestibility of the unsaturated fat relative to the saturated fat content in the dietary fat [34]. However, Müller et al. [33] found that supplementation of fatty acid in iso-energy diets with positive energy balance had no remarkable impact on metabolism of total lipids. There were also no significant differences observed among the proximate composition of the breast and thigh meat of broilers, except for the fat content in breast meat. Zollitsch et al. [24] reported no significant impact of different dietary fat sources (soybean oil, animal/vegetable fat blend, rapeseed oil, and processed fat product) on the chemical composition of broiler meat. A study revealed that fatty acid supplementation (3.0-3.4 g/d CLA) had no significant effect on body composition $[36,37]$. However, several studies showed that fatty acid can influence meat quality. Park et al. [38] observed that a $0.5 \%$ conjugated linoleic acid (CLA) diet significantly elevated whole body protein, water, and ash in rats. Müller et al. [33]] demonstrated the impact of CLA on improvement of protein deposition in mice and pigs. Feeding CLA to pigs tended to increase the firmness of the belly and the lean meat content, as well as to improve other aspects of meat quality in growing-finishing pigs [39]. A study in mice study indicated that CLA feeding induced a rapid and remarkable decrease of fat accumulation and an elevation of protein deposition [38], and was able to repartition the body fat to lean in rats [40]. Dugan et al. [41] reported that pigs fed CLA decreased subcutaneous fat accumulation by $6.8 \%$, and gained $2.3 \%$ more lean than pigs fed control diet. The lower fat content in the DF1, DF3 and 


\begin{tabular}{|c|c|c|c|c|c|c|c|c|}
\hline Item & & DF1 & DF2 & DF3 & DF4 & DF5 & SEM & P-value \\
\hline \multicolumn{9}{|c|}{ Thigh meat (g/100 of total fatty acids) } \\
\hline Myristic acid & C14:0 & 0.51 & 0.59 & 0.65 & 0.66 & 0.72 & 0.07 & 0.537 \\
\hline Palmitic acid & C16:0 & $19.48^{b}$ & $22.80^{\mathrm{a}}$ & $23.98^{a}$ & $23.16^{\mathrm{a}}$ & $23.41^{\mathrm{a}}$ & 0.33 & 0.002 \\
\hline Stearic acid & C18:0 & $6.05^{c}$ & $6.24^{c}$ & $7.19^{a}$ & $7.06^{\mathrm{ab}}$ & $7.02^{\mathrm{ab}}$ & 0.20 & 0.048 \\
\hline Arachidic acid & $\mathrm{C} 20: 0$ & 0.46 & 0.47 & 0.37 & 0.57 & 0.58 & 0.05 & 0.190 \\
\hline Total SFA & & $26.50^{c}$ & $30.10^{\mathrm{b}}$ & $32.19^{a}$ & $31.45^{\mathrm{ab}}$ & $31.74^{\mathrm{a}}$ & 0.35 & 0.001 \\
\hline Palmitoleic acid & C16:1 & $3.90^{\mathrm{b}}$ & $5.66^{\mathrm{a}}$ & $3.91^{\mathrm{b}}$ & $5.37^{\mathrm{a}}$ & $5.39^{\mathrm{a}}$ & 0.27 & 0.038 \\
\hline Oleic acid & C18:1 & $33.30^{\mathrm{b}}$ & $40.04^{a}$ & $30.67^{b}$ & $40.44^{a}$ & $41.47^{\mathrm{a}}$ & 1.00 & 0.022 \\
\hline Eicosenoic acid & $\mathrm{C} 20: 1$ & $1.38^{\mathrm{c}}$ & $1.49^{\mathrm{bc}}$ & $1.63^{\mathrm{ab}}$ & $1.58^{\mathrm{bc}}$ & $1.80^{\mathrm{a}}$ & 0.05 & 0.022 \\
\hline Nervonic acid & $\mathrm{C} 24: 1$ & $1.02^{\mathrm{c}}$ & $1.06^{\mathrm{c}}$ & $1.32^{\mathrm{a}}$ & $1.13^{\mathrm{bc}}$ & $1.25^{\mathrm{ab}}$ & 0.03 & 0.012 \\
\hline Total MUFA & & $39.60^{\mathrm{b}}$ & $48.24^{a}$ & $37.52^{b}$ & $48.52^{\mathrm{a}}$ & $49.91^{a}$ & 1.16 & 0.003 \\
\hline Linoleic acid & C18:2 (n-6) & $28.38^{a}$ & $16.28^{b}$ & $15.60^{\mathrm{b}}$ & $14.39^{\mathrm{b}}$ & $14.27^{\mathrm{b}}$ & 0.97 & 0.001 \\
\hline Eicosadienoic acid & $\mathrm{C} 20: 2(\mathrm{n}-6)$ & $0.32^{\mathrm{c}}$ & $0.42^{\mathrm{a}}$ & $0.41^{\mathrm{ab}}$ & $0.33^{\text {bc }}$ & $0.38^{\mathrm{abc}}$ & 0.02 & 0.063 \\
\hline DGLA & $\mathrm{C} 20: 3(n-6)$ & $0.87^{\mathrm{a}}$ & $0.78^{\mathrm{ab}}$ & $0.77^{\mathrm{ab}}$ & $0.66^{\mathrm{b}}$ & $0.70^{\mathrm{ab}}$ & 0.03 & 0.123 \\
\hline Arachidonic acid & $\mathrm{C} 20: 4(n-6)$ & 2.50 & 2.36 & 2.11 & 2.47 & 2.30 & 0.14 & 0.669 \\
\hline Total $\mathrm{n}-\mathbf{6}$ & & $32.07^{a}$ & $19.85^{b}$ & $18.89^{b}$ & $17.85^{\mathrm{b}}$ & $17.65^{\mathrm{b}}$ & 0.93 & 0.001 \\
\hline Alfa-linoleic aicd & C18:3 (n-3) & 1.74 & 1.54 & 1.56 & 1.55 & 1.51 & 0.07 & 0.314 \\
\hline Eicosapentanoic acid & $\mathrm{C} 20: 5(\mathrm{n}-3)$ & $0.51^{\mathrm{ab}}$ & $0.60^{\mathrm{a}}$ & $0.57^{\mathrm{ab}}$ & $0.45^{\mathrm{ab}}$ & $0.41^{b}$ & 0.03 & 0.154 \\
\hline Docosahexaenoic acid & $\mathrm{C} 22: 6(n-3)$ & $1.86^{\mathrm{a}}$ & $1.62^{\mathrm{ab}}$ & $1.53^{\mathrm{ab}}$ & $1.61^{\mathrm{ab}}$ & $1.43^{b}$ & 0.07 & 0.124 \\
\hline Total $\mathrm{n}-\mathbf{3}$ & & $4.11^{\mathrm{a}}$ & $3.77^{\mathrm{ab}}$ & $3.66^{\mathrm{b}}$ & $3.61^{\mathrm{b}}$ & $3.35^{\mathrm{b}}$ & 0.11 & 0.048 \\
\hline Total PUFA & & $36.18^{a}$ & $23.62^{\mathrm{b}}$ & $22.54^{b}$ & $21.46^{\mathrm{b}}$ & $21.01^{\mathrm{b}}$ & 0.94 & 0.001 \\
\hline $\mathrm{H} / \mathrm{H}$ & & $3.48^{a}$ & $2.72^{\mathrm{b}}$ & $2.16^{c}$ & $2.60^{\mathrm{b}}$ & $2.59^{b}$ & 0.07 & 0.001 \\
\hline MUFA/SFA & & $1.49^{a}$ & $1.60^{\mathrm{a}}$ & $1.17^{b}$ & $1.54^{\mathrm{a}}$ & $1.57^{\mathrm{a}}$ & 0.04 & 0.004 \\
\hline PUFA/SFA & & $1.37^{\mathrm{a}}$ & $0.79^{b}$ & $0.70^{b}$ & $0.68^{b}$ & $0.66^{b}$ & 0.04 & 0.001 \\
\hline$n-6 / n-3$ & & $7.81^{a}$ & $5.27^{b}$ & $5.16^{b}$ & $4.94^{b}$ & $5.27^{b}$ & 0.26 & 0.006 \\
\hline
\end{tabular}

Table 5: Effect of dietary fat sources on thigh meat fatty acid content in broilers.

DF5 group than that of DF4 indicated the leanness of broiler meat, which could be the beneficial outcome of the present study.

\section{Breast and thigh meat fatty acid profile}

The composition of poultry meat can be modified by a dietary approach, in which fat and oil sources are important dietary ingredients that can potentially be reflected in the animal products because of their enrichment of energy and fatty acid pattern [42]. Adipose tissues are affected by dietary fat. Some polyunsaturated fatty acids (PUFA), such as linoleic and linolenic acid are essential for humans and animals [27] and must therefore be added into the diet. There is evidence that feeding with certain fatty acids will affect the levels of essential fatty acids in broiler meat [30]. Chicken meat can be a source for these essential fatty acids for humans. However, when fat supplementation is performed in broilers, carcass fat quality must be considered because dietary fatty acids that show little change can greatly affect the body fat as well [30]. The saturated fatty acids (SFAs) in the muscle of poultry depends on the presence of fatty acids in the diet and synthesis in the liver [43]. The synthesis of SFA is inhibited in the liver to a greater extent during digestion of unsaturated fats than saturated fats [44]. In addition, increases in PUFA can influence suppression of the synthesis of monounsaturated fatty acid (MUFA) through inhibition of the action of 9-desaturase enzyme complex, which is the principal enzyme responsible for conversion of the SFA to MUFA [27]. Consistent with the present study, Azman et al. [35] reported an increase in PUFA and a decrease in SFA after dietary inclusion of soybean oil in broilers. For swine feed, also it creates attention to the nutritionist to formulate the feed with natural feed resources including higher content of PUFA, n-3 PUFA and CLA to enrich these contents into the pork for human health aspects [45]. Addition of vegetable oil (soybean oil, corn oil and sunflower oil) in the diet of non-ruminants results elevation of PUFA percentage which are the consumer demanded healthier products [46]. The suppression of SFA and elevation of PUFA in the meat of DF1 group mainly resulted due to diminution of palmitic (C16:0) and stearic acid (C18:0) and upgradation of linoleic (C18:2n-6) and alfa-linoleic acid (C18:3n-3). The DF1 containing higher linoleic acid levels (51\%) which might have influence on elevation of linoleic acid in the meat of broilers relative to other fat groups (DF2, DF3, DF4 and DF5). Linoleic acid $(\mathrm{C} 18: 2 n-6)$ is an essential fatty acid that acts as the primary precursor of $n-6$ PUFAs [7]. Linoleic acid in the diet can suppress lymphocyte proliferation in rats [47]; and alfa-linoleic acid can prevent cardiovascular disease [48], which all could be beneficial for human health through consumption of broiler meat. Eicosapentanoic acid (EPA) was found to be higher in DF2 than DF5 both for breast and thigh meat in the present study. Eicosapentanoic acid is an important fatty acid that is the precursor of eicosanoids (prostaglandins, thromxoxanes, prostacyclins, and leukotrienes) and important to brain function and vision [49]. Such types of fatty acids are important to human health since they are precursors for the biosynthesis of eicosanoids, which are considered an important bio-regulator of many cellular metabolic processes, blood pressure and clotting, tissue growth and immune system modulation [50].

Petrović et al. [51] reported that plant fat sources (hempseed oil containing $\gamma$-linolenic and stearidonic acid) induces health benefits against cardiovascular diseases, rheumatoid arthritis and dermatitis when consumed. The n-3 PUFA has a number of beneficial effects in humans and animals, such as reducing circulating cholesterol concentrations and reducing the risk of heart disease [52,53]. A fashion 
of higher alfa-linoleic acid (ALA) and lower arachidonic acid (AA) was exhibited in the breast meat of DF1 group and vice versa for DF3 group which might be attributable to the action of desaturase enzyme. An increase in n-3 PUFA, especially alfa-linoleic acid in the muscle may cause a substantial decrease in arachidonic acid because of the action of delta-6/5-desturase enzymes in the elongation and desaturation metabolism [54]. In the present study, a difference in the SFA and PUFA was apparent; however, no impact on MUFA was observed in the case of breast meat. Valencia et al. [55] reported that when different fat sources are added to the diet, monounsaturated fatty acids have a minimal effect, whereas saturated and polyunsaturated fatty acids have a profound effect. There was a higher PUFA/SFA ratio in the DF1 fed group than the other fat fed groups in the current study for both breast and thigh meat. This result is most desirable by the consumers since this phenomenon exhibits positive health benefits for humans through protection against cardiovascular disease [6]. In support of the results of the present study, previous studies have shown that the use of vegetable oils as a dietary source to improve PUFA/SFA in meat are recommended [56]. A decrease in the ratio of n-6 to n-3 PUFA in the animal fat group (DF2, DF3, DF4 and DF5) compared to the plant fat group (DF1) was exhibited in breast meat. Consistently, study conducted by Skrivan et al. [57] demonstrated that substitution of rapeseed oil by lard can decrease the n- 6 to n-3 PUFA ratio. A dietary ratio of n- 6 to $n-3$ PUFA is recommended at $4: 1$ to $7.5: 1$ by several international organizations to decrease the risk of cardiovascular disease [58-60] and a ratio of 10:1 and 2:1 is reported as the associates of negative consequence on health [61-64]. However, present result revealed that, dietary inclusion of fats in the diet of broilers ensures the n- 6 to n-3 PUFA ration with minimum and not exceed the higher or lower limit (10:1 or 2:1) which could be negatively impacted on the human health.

\section{Conclusion}

The effects of dietary fat sources with different fatty acid content was evaluated in broilers on carcass characteristics, breast and thigh meat chemical composition and fatty acid profile in broilers. No significant impact on relative organ weight were observed in response to the addition of different fat sources. Breast meat crude fat content was suppressed in DF1 and DF5 relative to DF4 group. Total SFA content was downtrended and total PUFA content was elevated in DF1 group relative to other groups for both breast and thigh meat. The $n-3$ PUFA was not affected by the fat sources in breast meat, whereas it was elevated in DF1 relative to DF3, DF4 and DF5 in thigh meat. The PUFA to SFA upgraded in DF1 and DF3 and downgraded in DF2, DF4 and DF5 for breast meat; and upgraded in DF1 than other groups for thigh meat. Breast and thigh meat n-6 to n-3 PUFA was upgraded in the DF1 group compared to other groups. Results indicated that dietary fat sources with different fatty acid content can significantly influence the breast and thigh meat composition and fatty acid profile without negative impact on the relative organ weight. Among fat treatments, DF1 (corn-soybean meal based basal diet + soybean oil) exhibited better result based on fatty acid profile and lower breast meat fat content which can be preferred for quality broiler meat production.

\section{Acknowledgements}

This work was conducted with the support of the "Cooperative Research Program for Agriculture Science \& Technology Development (Project title: Development of livestock production manual for halal certification and substantiation studies (Phase 1), Project No. PJ0122822016)" through the Rural Development Administration, Republic of Korea.

\section{References}

1. Howe P, Meyer B, Record S, Baghurst K (2006) Dietary intake of long-chain $\omega-3$ polyunsaturated fatty acids: contribution of meat sources. Nutri 22: 47-53.
2. Sioen IA, Pynaert H, De Backer G, Van Camp J, De Henauw S (2006) Dietary intakes and food sources of fatty acids for Belgian women, focused on $n-6$ and n-3 polyunsaturated fatty acids. Lipids 41 : $415-422$.

3. Mori TA, Burke V, Puddey IB, Watts GF, O'Neal DN, et al. (2000) Purified eicosapentaenoic and docosahexaenoic acids have differential effects on serum lipids and lipoproteins, LDL particle size, glucose, and insulin in mildly hyperlipidemic men. America J Clinic Nutri 71: 1085-1094.

4. Delarue J, LeFoll C, Corporeau C, Lucas D (2004) N-3 long chain polyunsaturated fatty acids: a nutritional tool to prevent insulin resistance associated to type 2 diabetes and obesity? Reproduct Nutrl Develop 44: 289-299.

5. Pérez-Matute $P$, Pérez-Echarri N, Martínez JA, Marti A, Moreno-Aliaga $M J$ (2007) Eicosapentaenoic acid actions on adiposity and insulin resistance in control and high-fat-fed rats: Role of apoptosis, adiponectin and tumour necrosis factor- $\alpha$. British J Nutri 97: 389-398.

6. Krauss RM, Eckel RH, Howard B, Appel LJ, Daniels SR, et al. (2001) Revision 2000: Statement for healthcare professionals from the nutrition committee of the American Heart Association. J Nutri 131: 132-146.

7. Russo GL (2009) Dietary $n-6$ and $n-3$ polyunsaturated fatty acids: from biochemistry to clinical implications in cardiovascular prevention. Biochemical Pharmacol 77: 937-946.

8. Yang X, Zhang B, Guo Y, Jiao P, Long F (2010) Effects of dietary lipids and Clostridium butyricum on fat deposition and meat quality of broiler chickens. Poultry Sci 89: 254-260.

9. Crespo N, Esteve-Garcia E (2002) Nutrient and fatty acid deposition in broilers fed different dietary fatty acid profiles. Poultry Sci 81: 1533-1542.

10. Guillevic M, Kouba M, Mourot J (2009) Effect of a linseed diet or a sunflower diet on performances, fatty acid composition, lipogenic enzyme activities and stearoyl-CoA-desaturase activity in the pig. Livestock Sci 124: 288-294.

11. Hulan HW, Proudfoot FG, Ackman RG, Ratnayake WMN (1988) Omega-3 fatty acid levels and performance of broiler chickens fed redfish meal or redfish oil. Canadian J Animal Sci 68: 533-547.

12. Boggio SM, Hardy RW, Babbitt JK, Brannon EL (1985) The influence of dietary lipid source and alpha-tocopheryl acetate level on product quality of rainbow trout (Salmo gairdneri). Aquaculture 51: 13-24.

13. Waagbø R, Sandnes K, Torrissen OJ, Sandvin A, Lie $\varnothing$ (1993) Chemical and sensory evaluation of fillets from Atlantic salmon (Salmo salar) fed three levels of $n-3$ polyunsaturated fatty acids at two levels of vitamin E. Food Chem 46 361-366.

14. Wiseman $J(1984)$ Assessment of the digestible and metabolizable energy of fats for non-ruminants. Proceedings-Easter School in Agricultural Science, University of Nottingham.

15. Freeman CP (1984) The digestion, absorption and transport of fats-nonruminants. Fats in animal nutrition, Butterworths, London.

16. Ketels E, Georges DG (1989) Effect of ratio of unsaturated to saturated fatty acids of the dietary lipid fraction on utilization and metabolizable energy of added fats in young chicks. Poultry Sci $68: 1506-1512$

17. Bee G, Zimmermann A, Messikommer R, Wenk C (1994) Effect of different fats on the fatty acid pattern in the chyme of pigs, meeting pig and poultry nutrition.

18. Kim JH, Hwangbo J, Choi NJ, Park HG, Yoon DH, et al. (2007) Effect of dietary supplementation with conjugated linoleic acid, with oleic, linoleic, or linolenic acid, on egg quality characteristics and fat accumulation in the egg yolk. Poultry Sci 86: 1180-1186.

19. Bostami ABMR, Ahmed ST, Islam MM, Mun HS, Ko SS, et al. (2015) Growth performance, fecal noxious gas emission and economic efficacy in broilers fed fermented pomegranate byproducts as residue of fruit industry. Intl J Adv Res 3: $102-114$.

20. Bostami ABMR, Ahmed ST, Mun HS, Hong SB, Yang CJ (2016) Efficacy of Rhodopseudomonas containing multi-microbe probiotic on growth performance mortality and cecal microflora in broilers. Africa J Microbiol Res 10: 985-993.

21. Bostami ABMR, Sarker MSK, Yang CJ (2017) Performance and meat fatty acid profile in mixed sex broilers fed diet supplemented with fermented medicinal plant combinations. J Anim Plant Sci 27: 360-372.

22. Kim YJ, Bostami ABMR, Islam MM, Mun HS, Ko SY, et al. (2016) Effect of fermented ginkgo biloba and camelia sinensis-based probiotics on growth performance, immunity and caecal microbiology in broilers. Int J Poultry Sci 15: 62. 
Citation: Bostami ABMR, Mun HS, Yang CJ (2017) Breast and Thigh Meat Chemical Composition and Fatty Acid Profile in Broilers Fed Diet with Dietary Fat Sources. J Food Process Technol 8: 672. doi: 10.4172/2157-7110.1000672

23. Scislowski V, Bauchart D, Gruffat D, Laplaud PM, Durand D (2005) Effects of dietary $n-6$ or $n-3$ polyunsaturated fatty acids protected or not against rumina hydrogenation on plasma lipids and their susceptibility to peroxidation in fattening steers. J Animal Sci 83: 2162-2174.

24. Zollitsch W, Knaus W, Aichinger F, Lettner F (1997) Effects of different dietary fat sources on performance and carcass characteristics of broilers. Animal Feed Sci Technol 66: 63-73.

25. Ajuyah AO, Lee KH, Hardin RT, Sim JS (1991a) Changes in the yield and in the fatty acid composition of whole carcass and selected meat portions of broiler chickens fed full-fat oil seeds. Poultry Sci 70: 2304-2314.

26. Ajuyah AO, Lee KH, Hardin RT, Sim JS (1991b) Influence of dietary full-fat seeds and oils on total lipid, cholesterol and fatty acid composition of broiler meats. Canadian J Animal Sci 71: 1011-1019.

27. Pinchasov Y, Nir I (1992) Effect of dietary polyunsaturated fatty acid concentration on performance, fat deposition, and carcass fatty acid composition in broiler chickens. Poultry Sci 71: 1504-1512.

28. Zollitsch W, Wetscherek W, Lettner F (1992a) Use of rapeseed oil in chickens Archives for Poultry 56: 182-186.

29. Zollitsch W, Wetscherek W, Lettner F (1992b) Use of fattened soybeans in chicken fattening. Archiv für Geflügelkunde 56: 256-263.

30. Scaife JR, Moyo J, Galbraith H, Michie W, Campbell V (1994) Effect of different dietary supplemental fats and oils on the tissue fatty acid composition and growth of female broilers. British Poultry Sci 35: 107-118.

31. AOAC (2000) Official methods of analysis of the association of official analytical chemists. Gaithersburg, MD, USA

32. O'Fallon JV, Busboom JR, Nelson ML, Gaskins CT (2007) A direct method for fatty acid methyl ester synthesis: application to wet meat tissues, oils, and feedstuffs. J Animal Sci 85: 1511-1521.

33. Müller HL, Kirchgessner M, Roth FX, Stangl GI (2000) Effect of conjugated linoleic acid on energy metabolism in growing-finishing pigs. J Ani Physiol An Nutri 83: 85-94.

34. Kirchgessner M, Ristic M, Kreuzer M, Roth FX (1993) Use of fats with high levels of free fatty acids in the Broilermast. II: Growth and quality of carcasses meat and fat in the gradual exchange of saturated by unsaturated fatty acids. Archiv für Geflügelkunde 57: 265-274.

35. Azman, MA, Konar V, Seven PT (2004) Effects of different dietary fat sources on growth performances and carcass fatty acid composition of broiler chickens. Revue de médecine vétérinaire 155: 278-286.

36. Berven G, Bye A, Hals O, Blankson H, Fagertun H, et al. (2000) Safety of conjugated linoleic acid (CLA) in overweight or obese human volunteers. Europe J Lipid Sci Technol 102: 455-462.

37. Zambell KL, Keim NL, Van Loan MD, Gale B, Benito P, et al. (2000) Conjugated linoleic acid supplementation in humans: Effects on body composition and energy expenditure. Lipids 35: 777-782.

38. Park Y, Storkson JM, Albright KJ, Liu W, Pariza MW (1999) Evidence that the trans-10, cis-12 isomer of conjugated linoleic acid induces body composition changes in mice. Lipids 34: 235-241.

39. O'Quinn PR, Nelssen JL, Goodband RD, Unruh JA, Woodworth JC, et al (2000) Effects of modified tall oil versus a commercial source of conjugated linoleic acid and increasing levels of modified tall oil on growth performance and carcass characteristics of growing-finishing pigs. J Animal Sci 78: 2359-2368.

40. Park Y, Albright KJ, Liu W, Storkson JM, Cook ME, et al. (1997) Effect of conjugated linoleic acid on body composition in mice. Lipids 32: 853-858.

41. Dugan MER, Aalhus JL, Schaefer AL, Kramer JKG (1997) The effect of conjugated linoleic acid on fat to lean repartitioning and feed conversion in pigs. Canadian J Animal Sci 77: 723-725.

42. Duran-Montgé P, Lizardo R, Torrallardona D, Esteve-Garcia E (2007) Fa and fatty acid digestibility of different fat sources in growing pigs. Livestock Sci 109: 66-69.

43. Jung S, Choe JH, Kim B, Yun H, Kruk ZA, et al. (2010) Effect of dietary mixture of gallic acid and linoleic acid on antioxidative potential and quality of breast meat from broilers. Meat Sci 86: 520-526.

44. Sim JS, Qi GH (1995) Designing poultry products using flaxseed. Flaxseed in human nutrition, American oil chemist's society press pp: $315-333$
45. Boselli E, Pacetti D, Lucci P, Di Lecce G, Frega NG (2008) Supplementation with high-oleic sunflower oil and a-tocopheryl acetate: Effects on meat pork lipids. European J Food Sci Technol 110: 381-391.

46. Mitchaothai J, Yuangklang C, Wittayakun S, Vasupen K, Wongsutthavas S, et al. (2007) Effect of dietary fat type on meat quality and fatty acid composition of various tissues in growing-finishing swine. Meat Sci 76: 95-101.

47. Yaqoob P, Newsholme EA, Calder PC (1994) The effect of dietary lipid manipulation on rat lymphocyte subsets and proliferation. Immunol 82 603-610.

48. Sposito AC, Caramelli B, Fonseca FA, Bertolami MC, Afiune Neto A, et al. (2007) Brazilian guideline on dyslipidemia and prevention of atherosclerosis: Department of Atherosclerosis of the Brazilian Society of Cardiology. Arquivos Brasileiros de Cardiologia 88: 2-19.

49. Dyall SC, Michael-Titus AT (2008) Neurological benefits of omega- 3 fatty acids Neuromolecular Medicine 10: 219-235.

50. Mao Z, Fu H, Nan Z, Wan C (2015) Fatty acid, amino acid, and minera composition of four common vetch seeds on Qinghai-Tibetan plateau. Food Chem 171: 13-18.

51. Petrović M, Debeljak Ž, Kezić N, Džidara P (2015) Relationship between cannabinoids content and composition of fatty acids in hempseed oils. Food Chem 170: 218-225.

52. Phetteplace HW, Watkins BA (1990) Lipid measurements in chickens fed different combinations of chicken fat and menhaden oil. J Agri Food Chem 38 : 1848-1853.

53. Simopoulos AP (2000) Human requirement for N-3 polyunsaturated fatty acids Poultry Sci 79: 961-970.

54. Nuernberg K, Kuechenmeister U, Kuhn G, Nuernberg G, Winnefeld K, et al. (2002) Influence of dietary vitamin $E$ and selenium on muscle fatty acid composition in pigs. Food Res Int 35: 505-510.

55. Valencia ME, Watkins SE, Waldroup AL, Waldroup PW, Fletcher DL (1993) Utilization of crude and refined palm and palm kernel oils in broiler diets. Poultry Sci 72: $2200-2215$

56. Mercier Y, Gatellier P, Vincent A, Renerre M (2001) Lipid and protein oxidation in microsomal fraction from turkeys: influence of dietary fat and vitamin supplementation. Meat Sci 58: 125-134.

57. Skrivan M, Skrivanova V, Marounek M, Tumova E, Wolf J (2000) Influence of dietary fat source and copper supplementation on broiler performance, fatty acid profile of meat and depot fat, and on cholesterol content in meat. British Poultry Sci 41: 608-614.

58. Simopoulos AP (1989) Summary of the NATO advanced research workshop acids: Biological effects and nutritional essentiality. J Nutri 119: 521- 528.

59. Kafatos A, Codrington CA (1999) Nutrition and diet for healthy lifestyles in Europe: The "Eurodiet" project. Public Health Nutri 2: 327-328.

60. Fernandes J (2002) Nutrition and health Recommendations of the health council of the Netherlands regarding energy, proteins, fats and carbohydrates. Nederlands Tijdschrift voor Geneeskunde 146: 2226-2229.

61. Broughton KS, Johnson CS, Pace BK, Liebman M, Kleppinger KM (1997) Reduced asthma symptoms with n-3 fatty acid ingestion are related to 5-series leu- kotriene production. America J Clinic Nutri 65: 1011-1017.

62. Zhao G, Etherton TD, Martin KR, Gillies PJ, West SG, et al. (2007) Dietary alpha-lino-lenic acid inhibits proinflammatory cytokine production by peripheral blood mononuclear cells in hypercholesterolemic subjects. America J Clinical Nutrition 85: 385-391.

63. Ferguson LR, Harris PJ (1999) Protection against cancer by wheat bran: role of dietary fibre and phytochemicals. Europe J Cancer Prevent 8: 17-25.

64. Lopez-Bote CJ, Rey AI, Sanz M, Gray JI, Buckley DJ (1997) Dietary vegetable oils and $\alpha$-tocopherol reduce lipid oxidation in rabbit muscle. J Nutri 127: 1176-1182. 